\title{
Of Transitions and Transformations
}

I began formal research on the Chinese funeral services industry in May 2013. Before then, I had attended a couple of memorial services for friends and relatives in urban China (my wife is from the Chinese city of Nanjing). I had also witnessed about ten funerals in rural China, mostly as part of a research project I conducted in Shandong province during the late 1980s and early 1990s (Kipnis 1997). I had more recently written a book on the rapid urbanization of a formerly rural county in Shandong (Kipnis 2016), and the combination of these research experiences suggested to me that a project on the urban funeral sector would reveal much about contemporary China. Funerals in rural areas had a very local mode of organization. Villagers who suffered a death in their family would ask village or lineage elders to organize the ritual and bury the deceased on village land. But those living in urban areas rarely had any contact with "familial elders" other than their own parents. Consequently, when dealing with the death of a parent they had neither a person to help organize the ritual nor land on which to bury the body.

Urbanization as a social transformation involves the creation of densely inhabited areas without land for burials and the formation of a population of people who live in nuclear families. This transformation requires a total rethinking of the process of conducting funerary ritual. In addition, the organization of urban funerals as a for-profit business is a product of the post-Mao (1978-) era of commercialization and urban social reorganization. During the Maoist era, work units (单位) tightly controlled most aspects of urban Chinese lives, including the conduct of death rituals. The history of the urban Chinese funerary industry thus also illuminates much about transformations in the Chinese economy during the post-Mao era.

Finally, I imagined that research on urban funerals could illuminate several aspects of the political regulation of state-society relations. The death of a loved one pushes everyone to deal with questions of the significance of life, regardless 
of the presence or absence of particular systems of religious belief. In a country where religious expression is permitted but regulated and "superstitious practices" are supposedly banned, how should the body and soul of a loved one be treated? Tensions around this question pervade the official treatment of funerals. In addition, the strong emotions associated with death can become a source of political energy. Funerals involve semi-public gatherings of groups of people who share a relationship through the deceased. Political movements often transform collective grief into political/moral outrage by turning the deceased into a martyr who died for a particular cause. In a country where all forms of political protest are discouraged, what do the politics of mourning reveal?

To conduct research for this project, I undertook several types of activities. First, I interviewed people involved in the funeral business, including one-stop dragon entrepreneurs; those who worked in state-run funeral homes and graveyards; Buddhist, Christian, and Muslim religious practitioners who sometimes conducted religious rituals in relation to death; nurses and administrators in old-age homes; and those who worked in the government, either regulating the funeral industry or arranging funerals for poor people and party cadres. Overall, I conducted formal interviews with fifty-five such people, in several cases more than once. I also conducted informal interviews with many people on the fringes of the business, such as those who sold flowers in front of cemeteries. Second, inquiring only among my own friends and my wife's relatives, I asked people who had arranged funerals for their parents to share their stories with me. I never approached people who had arranged the funeral for a child or who had recently conducted their funeral, as I imagined their grief would be too severe. I also always shared my own experiences (I, alongside my brother, have arranged the funerals of both my father and my mother). Though the sample of people from whom I collected stories cannot be considered representative, the depictions of fifteen funerals I collected in this manner were an important resource for this book. Third, I visited as many cemeteries as I could. Tombstones provide important clues about the families of the deceased. One can examine who is buried together as well as who is listed on the tombstone as a descendant. In cases where short eulogies or life histories are carved into the tombstone, one can examine what about the deceased-their soul, if you will-was deemed important enough to memorialize. Since different sections of a graveyard include the ashes of people buried at different times, one can make comparisons, examining how memorialization changes over time. Since graveyards can vary widely in terms of the cost of a burial plot, one can also make inferences about class differences in practices of memorialization. In addition, some tombs, mausoleums, and even cemeteries are central sites for state memorialization, state-sponsored political education, and propaganda. By comparing state practices of memorialization with those in graveyards for everyday people, one can trace the mutual influence of state preoccupations and a wider culture of practices of memorialization. In graveyards, one can also 
witness burial ceremonies. On holidays like Qing Ming, one can witness other practices of grave visiting and cleaning. Finally, as many forms of business in China maintain an online presence, I subscribed to the social media (Wechat) distribution lists of several enterprises in the funerary industry and visited the websites of many others.

In addition to these more formal research activities, I also had the opportunity to attend a few funerals during the course of my research, both because friends or relatives had passed away and because universities sometimes hold open funerals for famous professors, and I was associated with various universities during the course of this research. In all, I completed about eight months of research between 2013 and 2017. About three quarters of this research was conducted in Nanjing, but I also conducted interviews in Beijing, Jinan, Yinchuan, and Shanghai, and visited graveyards in several other cities as well. In 2018 and 2019, I had the chance to conduct research in several southern Chinese cities, including the separately governed Special Administrative Region of Hong Kong, where I was living. During this later period of research, I did not have time for any in-depth ethnography, but I did gain a better appreciation of both regional variation in funerary practice and the continuing evolution of government regulation of this sector.

In China, research on contemporary urban funerals is surprisingly rare. There have been important works in English written about funerary ritual in rural China and funerary ritual in the past (see especially Watson and Rawski 1988), but very little on contemporary urban funerary ritual. Two older works on this topic (Ikels 2004b; Jankowiak 1993) focus on conflicts over the forms of religious or "superstitious" elements to include in a funeral. While such conflicts still exist (see, for example, Colijn 2016), they were relatively rare in my research, perhaps because of the role of experts like Mr. Chen. During the period when Jankowiak conducted his research (over thirty years ago), or even Ikels (over twenty years ago) one-stop dragon entrepreneurs like Mr. Chen were not common. More important, neither Ikels nor Jankowiak focuses on the role of urbanization per se in the conduct of funerals. In the Chinese-language literature, publications on this topic are just as rare. Among academics interested in funerals in China, discourses of tradition and authenticity loom large; since facets of life like funerary ritual belong to the category of "traditional culture," researchers assume that the most "authentic" forms are to be found in the past and among those living in rural areas. Modernity and urbanization are seen as contaminating purer forms of ritual, which derive their authenticity from their association with a rural past. But for me, the clues funerary ritual and memorial culture give us about contemporary processes of modernization and urbanization are more valuable than what they might tell us about Chinese traditional culture. In addition, as one Chinese scholar working on the history of rural funerals told me, for academics in the People's Republic of China, the very factors that make urban funerals politically interesting also make them 
dangerous to write about, particularly under the repressive academic environment instituted by Xi Jinping.

The funeral of Mr. Wang, as depicted in chapter 1, is both a factual depiction of an actual event and a work of fiction. I selected Mr. Wang's funeral for two reasons. First, it was a funeral about which I collected interview depictions from three separate people (the two sisters plus Mr. Chen) and, thus, one for which I had a relatively complete record. Second, it seemed typical in many ways for a funeral in Nanjing in 2014.

How might the depiction of Mr. Wang's funeral be considered a work of fiction? Anthropologists have often argued that ethnographic writing combines narrative techniques derived from the writing of fiction with factual research experiences (for an excellent synopsis of some of this literature, see Narayan 2012). I created the narrative of Mr. Wang's funeral from the narratives told to me by three people. Like many news stories and ethnographic depictions, it is a story based on stories told by other people, though the fact that I heard the story told by three different people does increase the reliability of my version. The elements of dialogue I present in my narrative are based on moments of dialogue told to me by those three people, but, by the time I translated them into English and recorded them on the pages above, that dialogue is already several degrees removed from what actually took place. The depiction is also fictive because for purposes of maintaining anonymity I changed a few details (Mr. Wang and Mr. Chen, for example, are both pseudonyms). In addition, in places where I did not have enough detail to tell the story properly, I filled in details based on what I knew to be typical of the ritual process in Nanjing from other rituals I had seen and heard about. In this sense, the story of Mr. Wang's funeral might be seen as 90 percent coming from the funeral of a particular individual and 10 percent coming from my research in general.

In what ways was the funeral of Mr. Wang typical? First, consider the place and time of the event. In Nanjing, most people conduct the farewell meeting, cremation, and burial in the morning of a single day, an odd number of days after death. This was not the case in Beijing and Shanghai. In Nanjing, I was told that the reason for completing the process before noon was that the soul of the deceased was a "Yin" entity that would be damaged by the strong "Yang" that emanates from the afternoon sun. I suspect that this belief and practice were once fairly widespread in China, but that in large cities like Shanghai and Beijing, it is no longer practical. In Shanghai, the state-run funeral homes and the state-run crematorium are not usually located at the same facility (there are several funeral homes). Moreover, the graveyards are a long way from the center of town. Most critically, the ratio of the number of deaths on an average day to the number of time slots available for farewell meeting rooms at the state-run funeral homes is higher; consequently, it is not possible for all of the farewell meetings to be arranged in the morning. In Shanghai, I never heard anyone say that the entire funerary process should be 
completed before noon. But in many other smaller cities I visited, they also completed the entire process before noon. In Jinan they completed funerals for young people (those with a parent who was still alive) in the morning and old people in the afternoon. In Chongqing, according to the experience and research of a Chinese student of mine (Duan 2018), people set up tents in the public spaces between apartment buildings rather than constructing home altars.

The amounts of money involved in the economic transactions depicted in Mr. Wang's funeral also vary by place and time. In China's most expensive and coastal cities-like Shanghai, Beijing, and Guangzhou-everything would be more expensive. In cities further inland, prices would be lower. Moreover, the economy all over China has been growing. Prices for everything have risen, and the amount of money given for gifts has also increased. Twenty years ago, people would not have given cash gifts at funerals in Nanjing, but rather blankets or pieces of cloth. Since cash gifts at funerals became the norm, the amounts of money given have increased over time. In short, the funeral depicted in the last chapter was at best typical for a funeral conducted in Nanjing during the period of my research, though I think that people in many large Chinese cities would see significant similarities to funerals they have attended.

Other aspects of typicality have to do with the particularities of Mr. Wang and his family. Funerals for younger people can be radically different. Those who die in the prime of their working lives often see greater involvement of their employers in their funerals and a large number of colleagues attending. Funerals for the young are more painful affairs and can involve classmates and teachers if they are still at school. But old people pass away at a greater rate than the young, and husbands die before their wives more often than the other way around, so Mr. Wang's funeral was "typical" in the sense that he was an older man who passed away before his wife. Having three children and many nieces and nephews is also typical for urban Chinese people of Mr. Wang's generation. Those who were in their seventies and eighties at the time of my research had their children during the Maoist era, before the onset of China's birth planning regime, and typically had many children. They also worked during the peak of the urban planned economy and, thus, under the work unit structure of that era. As a consequence, they usually have reasonable pensions and often own apartments to which they gained rights during that era. The combination of multiple children and apartment ownership implies, unfortunately, that inheritance struggles are all too common in contemporary urban China. Several one-stop dragon entrepreneurs told me that incipient inheritance struggles were visible to them in over half of the funerals that they organized. One-stop dragon entrepreneurs also told me that religious practitioners are hired in less than 5 percent of the funerals that they organize, so Mr. Wang's funeral was also typical in that it did not involve any overtly religious elements, though it did involve many practices that could be considered "superstitious" from an orthodox communist point of view. 
Mr. Wang's funeral was also typical in terms of its size, level of expense, and grandeur. Mr. Wang and his children were neither particularly wealthy nor impoverished. As an older man, many of Mr. Wang's friends and colleagues were either dead or unable to leave their homes for extended periods in the winter, so most of those attending the funeral were Mr. Wang's younger relatives. According to interviews with people involved in the organizing of funerals at graveyards and funeral homes, as well as one-stop dragon entrepreneurs, larger funerals typically involve famous academics (who have taught many students who themselves are now academics), powerful cadres (who have appointed many people and thus have large networks of underlings, some of whom themselves are now powerful), rich businessmen, or people whose children occupy one of these positions. Mr. Wang and his children did not belong to any of these groups of people. Extremely impoverished people, or those with no living relatives, might have a state-sponsored ceremony which only a couple of people attend, but such funerals are also not so common. The types of funeral plots available and the style of tombstones at elite graveyards can differ drastically from those at Mr. Wang's graveyard, but, of the thirteen public cemeteries around Nanjing, only one was truly elite; the extent of variation among the rest was limited. Some impoverished people, or those particularly concerned with the ecology of wasting land for graves, might opt to have their ashes, or those of their loved ones, disposed of in a manner other than burial in a regular plot; they could, for example, have the ashes buried in a small wall vault or even scattered in the Yangtze River from a boat specifically designated for that purpose in a ceremony organized by the Nanjing Funeral Home. But, according to officials in the Nanjing funeral home, over 85 percent of Nanjing residents have their ashes buried in a regular sized plot.

Finally, many of the particular details of Mr. Wang's funeral, such as the throwing of coins from car windows, or the words spoken by Mr. Chen at the burial ceremony, would have been slightly different if a different one-stop dragon entrepreneur had organized the ritual. Many one-stop dragon entrepreneurs came from the rural areas surrounding the city. Often they got into this field of work because they or someone in their extended family had been involved in arranging funerals for their village. Since village custom can vary from place to place, the ritual particulars they bring with them can also vary. But the extent of this variation is easy to overstate. Though one-stop dragon entrepreneurs would claim that customary rural practice shifted every few kilometers, many of the logics behind particular forms of practice were consistent across places even when the details varied. Moreover, there have long been forms of state "orthopraxy" (that is, state sanctioned forms of orthodox funerary practice) in China. ${ }^{1}$ In addition, many current one-stop dragon entrepreneurs get ideas about how to arrange funerals from internet sources. Consequently, notions about what constitutes a proper ritual are widely shared. Few in the funeral industry would find the particular 
ritual prohibitions Mr. Chen admonished against, or the particular manner in which he arranged things, to be strange.

\section{OF TRANSITIONS AND TRANSFORMATIONS}

This book is about transitions and transformations of many types, but most basically about the relationship between the transition that a funeral marks-from a social situation in which a person is alive to one in which they are considered a memory or an ancestor-and the transformations in Chinese society that occur as it urbanizes, commercializes, and becomes more wealthy. The words transition and transformation have much in common, but are not quite the same. What do they share? Both words imply an entity shifting from one state to another, suggesting both change and continuity. The entity in its new state must differ from its old state, but must carry forward at least some of the aspects of its original being. Elsewhere, I have analyzed urbanization as a form of transformation and argued that all transformations are recombinant (Kipnis 2016). In transformations, elements organized in a particular way are recombined with some new elements to form an entity in a different state. While some of the elements from the pre-transformation entity are recognizable in the new entity, their position within the whole may have changed, or shrunk, or grown. The same might be said of a transition. What is different about the words, at least as I use them here, is that transitions are regular occurrences. The transitions of death in any human society are regular enough to be marked by a ritual, which we call a funeral. Transitions are transformations that occur so regularly, that are so expected, that we have standardized ways of dealing with them, even though their effects in any given instance might be shocking or revolutionary. Transitions tend to have clear temporal markers. Death occurs in moments and it is generally easy to mark the precise day and even hour at which death occurs. Puberty may take a bit longer, but generally takes place early in the second decade of a human life. Transformations are more open-ended. It is hard to say exactly when something like "urbanization" begins and ends, though we can point to moments when it seems to progress more quickly. Transitions themselves may transform. This book depicts transformations in funerary ritual, and the relation of ritual transformations to the transformations of urbanization. ${ }^{2}$

The transformation of funerary ritual in China is an ongoing affair that has neither a clear beginning nor a clear end; nevertheless, some of the broader transformations funerary ritual in Nanjing involves can be given a periodization. The rapid growth in the urban areas of China's largest cities has been especially apparent in the twenty-first century. In Nanjing, urban growth was strong but steady during the early reform era (with the urban area expanding at a rate of slightly over 1 percent a year), but really took off after 1995. Since then growth rates have exceeded 5 percent annually (Chen, Gao, and Yuan 2016). The geographic expansion of Nanjing has affected funerary ritual in many ways. The expansion of the 
city has involved the establishment, re-establishment, and relocation of the city's graveyards and the crematorium itself; shifts in the ways in which people move around the city; re-workings of the borders and relationships among the rural and urban districts of the wider urban area; the expansion of the population of the city, and the redefinition of citizenship in the city-that is to say, the extent to which Nanjing is a city of recent migrants versus a home to people who grew up in the urban area. It has also involved an increasing segregation of the spaces of the living from the spaces of the dead. Chapter 3 examines the relationship of these changes to the transformations of funerals by focusing on the spatial organization of death and death ritual.

Urbanization and modernization in Nanjing have been accompanied by transformations in the practices and patterns of kinship as well as the wider field of social networks in which people live. Household units have become smaller, and structured primarily around nuclear families, as many modernization theorists would suggest (Goode 1963; Yan 2003). But transformations in kinship patterns in China are much more complex than a straightforward modernization theory could predict. As Davis and Harrell (1993) pointed out over two decades ago, Chinese families have been shaped by the drastic policy shifts of the People's Republic of China as much as by processes of urbanization and industrialization. As is the case for Mr. Wang's family, family demographics have been strongly influenced by the generally pro-natalist policies of the early Maoist era followed by a gradual increase in inducements to reduce the number of children during the 1970 s and a strictly enforced birth planning policy during the post-Mao era. The result is a generational structure in which those born during the 1920s, 30s, and 40 often have several children, while those born in the 1950s, 1960s, and 1970 only have one. In addition, the privatization of the economy, especially of the housing stock, has meant that issues of inheriting property from parents have gone from being crucially important to one's class position during the pre-communist era (before 1949), to being unimportant during the Maoist era, to being of gradually rising importance during the post-Mao era. Today, after forty years of rising gradually, the inheritance of parental property has again reached a level of crucial importance. Contradictions between patrilineal ideologies of inheritance and a legal system that is not patrilineal result in considerable tension. Other shifts in social and familial relationships can likewise be seen as arising from a combination of urbanization and government policies. Yunxiang Yan has argued that both individuation $(2009,2010$ ) and descending familism (2016) (a form of familial commitment which prioritizes the development of youth over the authority of the elders) are becoming more prevalent.

Closely related to the rise of individualism (that is, the decreasing importance of familial relationships) is the rise of importance of relationships to strangers. As the funeral of Mr. Wang demonstrates, former strangers, like the one-stop dragon entrepreneur Mr. Chen, now often play a crucial role in these 
familial rituals. Chapter 4 explores transformations in the patterns of familial and wider societal relationships, as they are revealed in practices of death ritual and memorialization.

The urban economy has also transformed dramatically over the past forty years and this transformation both involves and goes beyond the specific policy measures national and local governments have taken to shape the economy. As might be expected in an economy that has steadily grown and become more unequal, there has been both an overall increase in the amounts spent on funerals and a greater degree of divergence between high-end and low-end practices of memorialization. During the Maoist era, funerals were often organized with the help of representatives from work units. As the work unit economy has gradually given way to the private economy, fewer and fewer people have work units to help organize funerals. This has created a business opening for one-stop dragon entrepreneurs. Before the twenty-first century, very few such businesses existed. At first they were even illegal, but over the first decade of the twentyfirst century they were tolerated and gradually became ubiquitous. The state-run crematoriums and funerals homes have also undergone considerable economic reorganization. They are increasingly asked to make themselves profitable at the same time that they are tasked with regulating conduct at funerals and providing low-cost funerals for the impoverished. Finally, as society becomes wealthier and older, larger companies are looking to move into the industry. They work closely with the government to both open new graveyards and disrupt the onestop dragon industry by introducing new web-based platforms to the funerary market sector. The economic transformations of funerary rituals are examined in chapter 5 .

Politically, funerals are sensitive occasions. Death can be an occasion for protest, for assigning blame or responsibility for the death to political actors. The strong emotions of grief can be transformed into forms of political passion. For this reason, the Chinese Communist Party regulates death and death ritual carefully, imposing its priorities wherever it can, but negotiating with other actors when the imposition of strict regulation threatens to result in too much resistance or indignation. ${ }^{3}$ In addition, when confronted with death, most families seek the expertise of people like Mr. Chen to obtain guidance on how to follow proper customary procedures. The tangle of rules, laws, and customs that govern funerary procedure are the topic of chapter 6 .

A final aspect of the transformation of funerary ritual has to do with conceptions of soul. This aspect of funerals is more abstract and difficult to pin down than funerary businesses or familial relationships, but still reveals much about contemporary Chinese society. The transition that funerals manage requires a concept of soul, of the animating spirit that seems to depart the body of a loved one when she or he dies. If funerals are about the reconstruction of social and cultural relationships among a group of people after one of its members is lost, then this 
recreation requires an assertion of continuity. How can the family continue when the deceased is no longer present? How can the values, the mission, the purpose for which the deceased stood for continue? How can the future remain connected to the past after the demise of the deceased? Thomas Laqueur (2015) suggests that all human societies use mortuary ritual to connect the past with the future. Imagining a soul allows something of the deceased to remain after his or her body perishes. The soul of Mr. Wang was addressed by his daughters, asked to last forever by the mourners, and given spirit money and flowers on several occasions. But exactly what this soul consists of, how it interacts with the living, and what sorts of agency it is seen as exerting all shift over time. Ideas about soul are often political because powerful people and organizations assert that they represent something that is immortal, unchanging, and everlasting. Such permanence adds to their mystique. Especially in a country like China, where "superstitious" activities are forced underground, explicit discussions of concepts like soul are quite rare. But they are nonetheless implicit in both funerary ritual and acts of memorialization at graveyards. They are also present in the widespread ideal of filial piety, which makes remembering deceased ancestors a form of moral obligation. Transformations in the treatment of the soul form the topic of chapter 7.

The final chapter of this book analyses ghosts. Ghosts haunt. They are present but not present, both real and figments of our imagination. Through the presentation of a ghost story, I return to the question of the relationship between fictional writing and truth and examine the psychological realities of haunting as they relate to processes of urbanization and political repression. From a secular, psychological point of view, souls can be seen as the aspects of a human that should persist over time, that should be memorialized to help us connect the past to the future. In contrast, ghosts haunt our memories whether we think they should be remembered or not. They remind us of that which is repressed, ignored, and forgotten. 